This is an Accepted Manuscript of an article published by Taylor \& Francis Group in Development in Practice on 6/06/2012, available online:

http://www.tandfonline.com/doi/abs/10.1080/09614524.2012.672953\#.U6w-X ldVHU

Published details:

Pells, Kirrily (2012)“'Risky lives': risk and protection for children growing up in poverty”, Development in Practice 22 (4): 562-673. DOI: 10.1080/09614524.2012.672953

The article is reproduced in accordance with the self-archiving policies of Taylor \& Francis Group. 


\title{
'Risky Lives': risk and protection for children growing-up in poverty
}

\begin{abstract}
Child protection has focused on responding to interpersonal violence and abuse. This approach can detach children from the broader socio-economic and political structures which shape their life chances, by concentrating on the symptoms of risk rather than the underlying causes. Drawing on the Young Lives study of childhood poverty, this paper argues that poverty and inequalities are at the heart of childhood risk, shaping which children are at risk and access to sources of protection and therefore to children's life chances. In order to protect children better, the child protection field needs to engage with the structured nature of risk.
\end{abstract}

Keywords: Youth, Health, Education, Development policies, Poverty reduction

\section{Kirrily Pells}

Kirrily Pells completed a PhD and postdoctoral fellowship on children and young people in postconflict situations with case studies of Rwanda and Bosnia. Kirrily has worked as a consultant for international organizations in the child protection field. She is currently a policy officer for the Young Lives study of childhood poverty.

Policy Officer, Young Lives, Department of International Development, University of Oxford, Oxford, OX1 3TB. Email: krrily.pells@qeh.ox.ac.uk 


\title{
'Risky Lives': risk and protection for children growing-up in poverty
}

\author{
Introduction
}

Child protection aims to 'prevent, respond and resolve the abuse, neglect, exploitation and violence experienced by children'. While acknowledging that the 'root causes of child protection failures' include 'chronic poverty, insecurity, power imbalances and harmful traditional attitudes and behaviours', in practice focus has been predominately on responding to interpersonal violence, abuse, and neglect experienced by children.(1) Such an approach encourages a focus on certain 'categories' of children, such as 'orphans and vulnerable children', perceived to be most exposed to risk, as well as extreme situations such as armed conflict, prostitution, and hazardous child labour. This approach also detaches children from the broader socio-economic and political structures that shape their life chances and trajectories, by concentrating on the symptoms of risk rather than the underlying causes of poverty and inequality.

Chronic poverty is a significant risk factor for poorer life chances, as well as increasing the chances of exposure to other risks, such as drought, illness, poor nutrition, harmful forms of labour, and poor quality, or lack of, services. Across the life course, these risks may have different impacts, as well as having cumulative effects lasting into adulthood and reinforcing the transmission of poverty and inequalities to the next generation (Boyden and Cooper 2009; UNICEF 2010). At the same time exposure to risk does not always result in negative outcomes. Among children growing up in adverse circumstances some fare better than others (Luthar et al. 2000; Werner and Smith 2001). Understanding the nature of risks faced by children, their households and communities, as well as sources of support and protection, is therefore essential in protecting children and improving their life chances.

Drawing on quantitative and qualitative data from the Young Lives study of international childhood poverty in Andhra Pradesh (India), Ethiopia, Peru and Vietnam, this paper argues that poverty and inequalities are at the heart of childhood risk, shaping which children are at risk, access to sources of protection, and therefore children's life chances. The paper begins with a discussion of risk, resilience, and protection before providing an overview of the Young Lives study. This is followed by three key sections. The first examines how disparities in children's life chances widen over the life course, with risks being cumulative and compounded, which, as discussed in the second section, frequently disadvantage the same children. The third section explores the complex interconnections between risk, protective processes and children's life chances, through the lens of family illness and death. The conclusions are that to protect children better, the child protection field needs to engage with the structured nature of risk faced by children, their households, and communities, and to build on sources of protection within them.

Risk, resilience and protection 
The concepts of risk and resilience have become increasingly popular in understanding the impact of negative circumstances on children's development, and factors that enable children to 'recover from, adapt to and/or remain strong in the face of adversity' (Boyden and Cooper 2009). While risk is understood as factors which increase the probability of negative outcomes, there is much less conceptual and methodological clarity over resilience, and this paper uses the term protective processes, suggesting ongoing actions that may moderate and mitigate the impact of risk on children and their families.

Research framing child protection issues in terms of risk, resilience and protective factors often tends to emphasize internal psychological processes over broader structural factors and social processes (Boyden and Cooper 2009; Crivello and Boyden 2011. For an exception see Werner and Smith 2001). Individualistic approaches target symptoms rather than the root causes of the problem and 'de-politicises the project of poverty reduction' (Boyden and Cooper 2009; Seccombe 2002). Moreover, it tends to result in a focus on categories of children 'at risk', such as orphans and vulnerable children, and crisis situations such as humanitarian disasters, rather than the underlying structural causes of risk. The subjective perceptions and collective understandings of those affected also tend to be overlooked in favour of 'objective' standards of negative and positive developmental pathways (Crivello and Boyden 2011).

Some factors may simultaneously represent risk and protection, implying that they can either contribute to or undermine life chances. For example, children may leave school in order to work to support the household because of the death of a caregiver. This may be a risk factor for the longer-term chances of the young person obtaining a higher-paid job and potentially may be damaging to their health and sense of well-being. At the same time this strategy stops the household from either disintegrating, starving or having to take out a loan at a high interest rate, and the child may develop more vocational skills and a sense of achievement by supporting the family. This is part of a series of trade-offs that families living in chronic poverty are forced to make (Kabeer 2000), especially in coping with adverse events, as emerges in the following sections.

\section{Young Lives and Methodology}

Young Lives is a longitudinal study of childhood poverty which has been collecting both survey and qualitative data on around 12,000 children since 2002 in four countries (Ethiopia, the Indian state of Andhra Pradesh, Peru and Vietnam). This paper focuses on the trajectories of an older cohort of children of around 1,000 children in each country (slightly fewer in Peru) born in 1994/95. Household and child-level data were collected on this group when they were 8, 12 and 15 years old. In-depth qualitative information was collected on 25 older cohort children in each country in 2007, 2008 and 2010/11. All the names of Young Lives children used in this paper are pseudonyms.

The study focuses on children growing up in poorer populations.(2) The data therefore are not nationally representative; nor should they be compared simplistically between the Young Lives countries, since the samples of children are drawn differently. Such panel data can, however, highlight how change over time is affecting children and what similar (or different) processes are taking place in each of the countries, as well as disparities within the samples. 
This paper uses three principal methods. Descriptive statistics are used to explore changes in children's life chances between the three survey rounds, disaggregated according to sociodemographic characteristics of the child and the household. Regression analysis is used to examine the impact of a series of potential risk and protective factors reported in 2006 upon school enrolment, cognitive achievement, self-rated health, BMI(Body Mass Index)-for-age, height-for-age and subjective well-being measured in 2009 of children in the Older Cohorts across all four countries. This includes the socio-demographic characteristics of the child and household, risk factors (including economic and environmental shocks, illness and death of a family member) and protective processes (including household membership of groups and level of support, and access to services). Although this analysis does not necessarily prove causality it can be used to illustrate factors which are associated with one another. Findings are supported further by interviews with children, their caregivers and community members, from Ethiopia and Andhra Pradesh.(3)

Recognising the methodological challenges in capturing the complexity of interactions between multiple potential risk and protective factors, this paper is cautious in attributing exact causation. Instead, it identifies channels through which factors may have a negative effect on children's life chances, such as lower levels of cognitive development or poor health, or may assist children and families in responding to risk.

\section{Cumulative and compounded risk}

For children growing up in poverty risk is 'an integral part of everyday "ordinary" lives in which the young negotiate multiple, interacting challenges' (Crivello and Boyden 2011: 1). Risk can be cumulative and compounded, with factors interacting with one another and thereby having an increasingly negative impact on children's life chances over time. This is explored in the following section, which examines children's trajectories through schooling and outcomes in formal learning.

Children's experiences of school and formal learning outcomes are shaped not only by their socio-economic status and household situation, but also by factors within school. These can include the quality of education received, challenges in the school environment such as lack of gender-segregated toilets or forms of corporal punishment, as well as differing attitudes and expectations of teachers for boys and girls (Pells 2011). Factors internal and external to the school environment may therefore hinder progression through school, increasing the risk of grade repetition and of children leaving school before they complete a full course of primary education.

This is illustrated by the case of Mohan, who was 15 years old at the time of data collection and from a Backward Caste in rural Andhra Pradesh. He stopped going to school after the seventh grade as his father was sick. He did not return to school, even though his parents encouraged him to do so. He said 'everyone will be new and I thought it will be awkward if I go back so I never went.' Previously he used to be beaten by teachers as he was absent frequently. Mohan also explains that in the future he will be responsible for supporting his parents as well as his own family when he marries, and says staying in school is 'risky'. He believes it is important to learn 
skills like his father, who is a mason, so that he can earn money to have a good life. Mohan lists the range of skills he has learnt from his father and older cousins including ploughing, driving a bulldozer, driving a bull cart, mending the tractor, building walls, and plastering.. It illustrates the series of trade-offs made by families living in chronic poverty and underscores the need to consider schooling in the broader context of economic development and whether it is equipping children like Mohan with the skills that they need in order to enter the local labour market.

Within Young Lives study countries, primary schooling has increased, particularly in areas and among groups with initially lower enrolment levels. Yet rising enrolment rates do not fully capture children's pathways through schooling and how and why these may vary between different children. Despite the different stages of economic development and socio-cultural contexts of the four countries, there is a consistent pattern of disparities, which widen over time. As the children become older, differences in school enrolment and cognitive achievement between non-poor children and poor children, between children living in urban and rural areas (illustrated by figure 1), and between groups with different social status because of ethnicity or caste, increase.

Figure 1. Widening gaps in school enrolment, Andhra Pradesh Older Cohort, $2002-9$ (n. = 1008)

Across all four countries household wealth (a composite measure which includes consumer durables, quality of housing, and access to services) is a predictor of school enrolment. As the children grow older, those from the poorest households are least likely to be enrolled and have lower levels of cognitive achievement. For example, in Vietnam the percentage point difference in school enrolment level between poor children and the rest more than tripled between the ages of 12 and 15. Controlling for other factors, the household position on the wealth index is also associated with children's cognitive achievement. Cognitive achievement is measured for all children, not just those in school, and the score used here combines two measures, one testing receptive vocabulary and the other testing maths. (4) The wealth index is constructed on a scale with 0 (minimum) and 1 (maximum). Across all four countries children who live in wealthier households performed better in the cognitive achievement tests. Each point on the wealth index accounted for 1.6 points on a five-point cognitive score of children in Andhra Pradesh, 1.7 points in Peru, 2 points in Vietnam and 2.2 points in Ethiopia.

In both Vietnam and Peru there is a large gap between children in the poorest quintile and the rest in terms of cognitive achievement. Further analysis suggests that this may be due to the marginalised status of ethnic minorities within the countries. This is illustrated by Figure 2, which shows that in Vietnam children from ethnic minorities are over three times more likely to be in the lowest category of cognitive achievement than their Kinh peers. Moreover, while the numbers of Kinh children in the bottom category declines between 2006 and 2009, there is no change among children from ethnic minorities. (5)

Figure 2. Children in the lowest and highest categories of cognitive achievement in Vietnam, according to ethnicity, 2006 (n. = 925) and 2009 (n. = 961)

A similar situation exists in Peru, where only 10 per cent of children from ethnic minorities attend bilingual schools, the rest receiving education in Spanish. Young Lives research also found that half the teachers in bilingual schools in southern Peru could not speak the local 
indigenous language and that bilingual materials were not being used (Cueto et al. 2009b). These disparities are indicative of an 'inverse care law' whereby poorer and more marginalised children often attend schools with fewer resources and receive a poorer-quality education (UNESCO 2010: 23).

While important, differentials between girls and boys are much smaller than between children living in urban areas and those living in rural areas (Pells 2011). This is a situation reflected across the countries. However, important trends are emerging as the children grow older which have implications for the reproduction of inequalities and children's transition beyond school to livelihoods, the labour market and the establishment of households of their own. Though within the Young Lives samples there was parity in the numbers of boys and girls going to primary school, national data show that this has been achieved in Vietnam and Peru, but that gender parity does not yet exist at primary level in Ethiopia and India (UNICEF 2010). By 2009 differences between boys and girls have become clearer yet, contrary to the dominant narrative of girls being consistently disadvantaged (Levine et al. 2008), within the Young Lives sample it is not always girls who fare less well. In Peru, Vietnam, and Ethiopia more boys than girls in the Older Cohort are leaving school by the age of 15 years. This could be due to the higher wageearning potential of boys, or boys performing less well in exams (UNESCO 2010: 67). In addition girls may be able to combine tasks at home with studying, but boys may find it harder to combine school with work, given the different types of work undertaken according to gender (Pells 2011).

In Peru and Ethiopia boys are increasingly outperforming girls in cognitive achievement tests over time. Conversely, in Vietnam the number of girls in the highest quintile of performance increasing, while the number of boys is decreasing. In Andhra Pradesh there is a consistent pattern of girls being disadvantaged, with boys 1.8 times more likely to be enrolled by in 2009 and performing better in cognitive achievement tests. This may become increasingly significant in the future, given the importance of maternal education for Young Lives children.

Studies have shown maternal education to be a significant factor in breaking the intergenerational transmission of poverty, as girls who stay in school for longer marry and have children later, so decreasing the risk of maternal and child mortality and morbidity (Levine et al. 2008; UNICEF 2010: 4). Children with mothers with no or little education tend to have lower levels of cognitive achievement, progress through school more slowly and leave school earlier.

More analysis is required to understand the relationship between maternal education and household socio-economic status. Although maternal education is a fairly robust proxy for other household factors, it is likely that it reflects rather than wholly drives household disadvantage. In other words, households with a history of disadvantage also tend to have mothers with lower levels of education. However, regression analysis that controlled for a series of variables including household wealth, found that children with more educated mothers tend to have higher cognitive test scores in all four countries. Each year of maternal education correlated with slight increases on the cognitive achievement scale. This may be because more highly educated mothers are better able to support children's formal learning and have higher bargaining power to allocate resources within the household to educational and healthy development (Levine et al. 2008: 20). 
In summary, Young Lives data on children's trajectories through school and outcomes in formal learning demonstrate that disparities increase over children's lives between non-poor children and poor children, between children living in urban and rural areas, and between groups with different social status because of ethnicity or caste. The differences between boys and girls also increase over time, although at a much lower rate than the other disparities. However, maternal education appears as a significant mediating factor: children with more highly-educated mothers have better life chances. Risks are cumulative and compounded across the life course, but often in more nuanced ways than commonly assumed, as illustrated by the complex picture concerning gender differences.

\section{Multiple disadvantages}

Chronic poverty and inequalities repeatedly disadvantage the same children, who are at a higher risk of having poorer outcomes in multiple areas of education, health and subjective well-being. This section brings together the education-related areas of the previous section with indicators of healthy development and nutrition. Inadequate nutrition, including insufficient food, poor micronutrient intake and disease at an early age can result in stunted growth. Young Lives data have demonstrated a number of consequences of stunting including poorer cognitive development in Vietnam (Le Thuc 2009) and Peru (Sanchez 2009). Stunting also impacts on children's subjective well-being, with children reporting higher levels of shame or embarrassment because of being shorter than their peers, and so is likely to impact on children's progression through school (Dercon 2008). It can also increase susceptibility to physical illness, as the body is less able to fight infections. Stunting therefore has long-term implications for children and also for the wider society, through lost potential.

As with inequalities relating to education, certain groups of children are more likely to be stunted than others. In all countries except India (Andhra Pradesh), higher household wealth is associated with greater chance of having a healthy height-for-age. (6) Similarly, in all four Young Lives study countries children in urban areas are more likely to have a healthy height-forage than their rural counterparts, with children in rural areas having lower access to quality services. Ethnicity is also a factor: there is a higher prevalence of stunting in Peru, Vietnam and Andhra Pradesh among children from ethnic minorities or lower-caste status, when controlling for other factors. Children who belong to the Scheduled Caste in Andhra Pradesh are 70 per cent less likely to have a healthy height-for-age, whereas in Vietnam children are 3.3 times more likely to be in the healthy range if they belong to the Kinh (majority) ethnic group. While groups with low social status tend to live in rural areas, the stunting rates for these groups are higher than the average for rural areas. This may be due to the difficulties associated with providing quality services in remote areas. It may also be a result of political economy whereby marginalised groups have less voice in demanding resources.

Poverty is also associated with lower subjective well-being. To collect data on children's perceptions of well-being, Young lives asked them to position themselves on a ladder where the ninth step represents the best possible life and the first step represents the worst. Across all four countries, controlling for other factors, higher household consumption levels are associated with children positioning themselves higher on the ladder. This suggests that poverty and inequalities 
impact on children's subjective well-being. Notably, higher levels of maternal education are associated with a higher position on the ladder in all countries except Vietnam, and with higher self-rated health in all except Ethiopia.

The overlap between better outcomes in enrolment and formal learning and indicators of health is illustrated more clearly by Table 1 . This disaggregates the number of cases of children in Peru with poor outcomes in one of the education and formal learning domains (enrolment or low cognitive achievement) and in proxies for health (out of the healthy range for BMI-for-age or height-for-age). The key issue is whether children from particular groups are over-represented.

Stark inequalities are highlighted by the over-representation of children from rural areas, ethnic minorities and households in the poorest quintile of household consumption. The make-up of the group of children showing less good enrolment, cognition and health indicators compared with the whole sample suggests that children from rural areas are 2.5 times less likely to fare well in life chances in both education and health. Similarly, children from ethnic minorities (1.5 times) and children from households in the poorest quintile of household consumption (1.3 times) are less likely to fare well. A similar picture emerges in Vietnam with children from ethnic minorities (over 1.5 times) and from households in the poorest quintile (1.3 times) being less likely to fare well in education and health, suggesting that in both countries there are highly marginalised groups.

Table 1. Distribution of children poor in education and health, Peru, 2009

In terms of scale, children with poor outcomes in one health-related and one education-related dimension are much greater in number in Andhra Pradesh and Ethiopia, with just over two-thirds of children in the Older Cohort in Andhra Pradesh and just under two-thirds of children in Ethiopia falling into this category. However, children from the poorest quintile of household consumption are only slightly over-represented in Andhra Pradesh and Ethiopia and not to the same extent as in Peru and Vietnam. Therefore, although poverty rates have declined in all four countries (Dornan, 2010) this has not necessarily resulted in the reduction in cumulative and compounded risk for the poorest and most marginalised groups in society. It demonstrates also the way in which risk is mediated through poverty and structural disadvantage.

Poverty and inequalities are at the root of risks for children

Children and families living in chronic poverty have fewer resources to cope with risks or adverse events such as illness and death, which therefore hit them harder and can perpetuate the cycle of poverty and risk. At the same time, where possible households draw on a range of strategies to cope with and respond to risk. Children play a key role in managing risk within the household. The following section explores the interconnections between risk, protective processes and children's life chances, through the lens of family illness and death, selected because of their prevalence in the everyday lives of poor children and families.

Illness is both a cause and consequence of poverty, due to the poor-quality living environment of poor children and the indirect (lost income and time) and direct costs (user fees at healthcare facilities, cost of medicines and transport to the facility) of illness. Illness also tends to co-occur 
with other types of adverse events, such as food-price increases, crop failure and drought . For example, in Ethiopia 52.6 per cent of households reporting an environmental shock also reported experiencing a family illness or death, and 53.9 per cent of households reporting an economic shock in 2009 also reported experiencing a family illness or death (Dornan, 2010: 9). The cooccurrence of adverse events and the impact of direct and indirect costs are illustrated by the situation faced by Harika's family.

Harika lives in a rural community in Andhra Pradesh with her parents and two brothers. Her family belongs to a Backward Caste. Harika's eldest brother was unwell and taken to a doctor in the town and initially diagnosed with malaria. When his condition did not improve, he was admitted to a private hospital in Hyderabad. After a series of tests, it was discovered that there was 'no circulation of blood on one of the nerves on [his] neck'. The entire ordeal lasted for one month, during which time Harika's mother stayed by her son's side and was unable to work the family's fields. According to Harika: 'We did not take care of the cotton fields and that was the reason the crop was not good.' The total cost of the treatment was 150,000 rupees, which the family paid by obtaining a loan at a low interest rate. Harika's maternal cousin helped to transport the family to Hyderabad and provided accommodation during their stay. On another occasion, Harika's father was unwell and Harika had to miss school in order to help her mother tend the fields. Harika says feels that her household is poorer as a result of these events.

Family illness and death can have long-term impacts on children. For example, controlling for other factors, children in Andhra Pradesh who lost a family member (other than a caregiver) are 70 per cent less likely to be enrolled in school. Evidence from the qualitative data suggests that this is due to children having to take over the roles and responsibilities previously undertaken by the family member. In both Ethiopia and Vietnam the death of a father is associated with lower cognitive achievement, perhaps suggesting periods of absence or permanent drop-out from school. Therefore, ill-health and illness need to be examined at the household level. This builds up a more complete picture, as not only does illness of one member impact on all the others, the entire household including children is involved in managing illhealth, as illustrated by Harika's family.

In managing ill-health and illness, children and families depend on multiple sources of support. Children and caregivers described employing a range of strategies. These may include reducing consumption, selling assets or using savings, labour substitution (by children or others), borrowing, seeking assistance from relatives, neighbours or NGOs, and/or use of social protection schemes. Families often employ several strategies simultaneously, as illustrated by the case of Denbel.

Denbel lives in urban Ethiopia with his single mother and younger brother. Denbel had malaria and he was taken to a private clinic, tested and provided with medication. The total cost of the treatment was 30 birr, which Denbel's mother 'borrowed ... with interest from our association in which we save money for buying meat for holidays'. The daily amount of interest on 30 birr is 90 cents and Denbel's mother repaid half of the loan within a week, reducing the daily interest to 45 cents. A neighbour provided Denbel with support during his recovery: 'The doctor told him to take the medication with milk. And [the] neighbour, who owns a cow, gave him one bottle of milk every day.' 
Denbel's case illustrates also the role of semi-informal community-based organizations (such as the self-help groups in Andhra Pradesh or burial societies called idirs in Ethiopia). Controlling for other factors, household membership of these groups is associated with better outcomes for children, including enrolment (Andhra Pradesh and Ethiopia), health (Andhra Pradesh, Ethiopia and Peru) and subjective well-being (Ethiopia). Access to informal networks enables families to cope better with illness.

However, there are also dangers associated with debt-traps, and ability to access credit is often dependent on the household's social standing within the community. As one caregiver in Ethiopia explained, 'Only those who are trusted by the kebele leaders can receive credit.'(7) Consequently access to these protective processes is frequently determined by the same inequalities of power and resources (such as income, livelihoods, assets, credit, insurance, quality of the living environment and access to quality services) that give rise to higher risk for poor families. This suggests a potential role for social protection, working alongside, rather than replacing, existing structures.

Rajesh is from a Scheduled Tribe and lives in rural Andhra Pradesh. His father contracted malaria and typhoid and was unable to work for a month. Faced with destitution, the family adopted a number of strategies. Rajesh and his siblings undertook work as part of the National Rural Employment Guarantee Scheme. (8) Rajesh did not have his own work card, so used his sister's during the holidays. Rajesh's elder sister also sought to help the family by providing 500 rupees for medical costs and his mother borrowed 1,500 rupees, with one per cent monthly interest, from a self-help group. As illustrated here social protection schemes provide poor families with more options, acting as an insurance or redistribution system, rather than a credit system, which entails debt.

\section{Conclusions}

While child protection is concerned with reducing risk and improving protection for children, it has the tendency to take the approach of enabling individual children to 'beat the odds' rather than 'changing the odds', which requires targeting the causes of poor life chances rather than just the symptoms (Seccombe 2002). Evidence from Young Lives challenges this approach by demonstrating that risk is driven by poverty and structural inequalities, repeatedly putting at a disadvantage the same groups of children, who fare less well across a series of indicators in education, health, and well-being. To protect children therefore, child protection needs to look beyond violence at the interpersonal level, to violence at the structural level.

However, there is the danger that child protection could be tasked with everything and consequently achieve nothing. An alternative and more feasible approach would be to place children at the centre of development debates and policies, integrating child protection concerns around sources of risk and protection. This would enable a shift from reaction to prevention and the injection of a political-economy perspective to understand how broader structural inequalities put children at risk. It would facilitate greater linking of the situation of children with that of their families and communities: risk and protective factors for children cannot be understood in isolation from families and communities. As poverty is compounded by multiple and recurrent adverse events, such as illness, there is also a need for policies that do not target one risk alone, 
since poor outcomes in one area, such as health, can undermine progress in another, such as education. Children and their caregivers offer insights into how formal schemes and informal networks do and do not work in mitigating the impact of poverty and adverse events on the household and should be used to inform policy. It is only by 'changing the odds' through such an approach that child protection will truly live up to its name.

Notes

1. Save the Children's definition on child protection, available at <http://sca.savethechildren.se/PageFiles/3189/child\%20protection\%20definition\%20SC.p df $>$ (accessed 29/09/11)

2. Details can be found in technical notes which describe the sample at <http://www.younglives.org.uk/our-publications/technical-notes > (accessed 29/09/11)

3. The term 'caregiver' has been used in recognition of the fact that children are not always cared for by their biological parents.

4. Receptive vocabulary (school readiness), verbal skills and achievement were measured using tests Young Lives developed from standardised international tests, such as the Peabody Picture Vocabulary Test (PPVT). Measures were adapted to local contexts and languages to minimize bias, an especially important consideration in testing children who speak minority languages. Reliability and validity results for test administrations and concerns are presented and discussed in Cueto et al. (2009a).

A composite cognitive achievement score was created by coding separately PPVT and maths scores into low, medium and high scores and then combining these variables.

5. The picture for children from ethnic minorities could be even bleaker. Regression analysis showed that if wealth were the same for both majority and minority groups, the majority Kinh group would be 80 per cent less likely than children from ethnic minorities to be enrolled in school.

6. BMI-for-age and height-for-age were calculated using international norms established by the World Health Organization. Children classified as having a healthy BMI and height fall within two standard deviations of the norm.

7. Kebele is the smallest administrative unit in Ethiopia.

8. The National Rural Employment Guarantee Scheme (NREGS) guarantees hundred days per year of wage employment doing unskilled manual work for adults in rural households. Although it is illegal for people under 18 years old to participate, children sometimes use family members' job cards to work on the scheme.

Acknowledgements

My thanks are due to the children and families who participate in the Young Lives study and to the data-gathering teams in the study countries. I am especially grateful to Laura Valadez and Daniel Vujcich for assistance with data analysis and to Paul Dornan for support in developing the article.

References 
Boyden, J. and E. Cooper (2009) 'Questioning the Power of Resilience: Are Children Up To the Task of Disrupting the Transmission of Poverty?' in J. Addison, D. Hulme and R. Kanbur (eds.) Poverty Dynamics: Measurement and Understanding from an Interdisciplinary Perspective, Oxford: Oxford University Press.

Crivello, G. and J. Boyden (2011) Situating Risk in Young People's Social and Moral Relationships: Young Lives Research in Peru, Working Paper 66, Oxford: Young Lives.

Cueto, S., J. Leon, G. Guerrero and I. Muñoz (2009a) Psychometric Characteristics of Cognitive Development and Achievement Instruments in Round 2 of Young Lives, Technical Note 15, Oxford: Young Lives.

Cueto, S., G. Guerrero, J. León, E. Seguin and I. Muñoz (2009b) 'Explaining and Overcoming Marginalisation in Education: A Focus on Ethnic/Language Minorities in Peru', background paper for EFA Global Monitoring Report 2010, Paris: UNESCO.

Dercon, S. (2008) Children and the Food Price Crisis, Policy Brief 5, Oxford: Young Lives.

Dornan, P. (2010) Understanding the Impact of Crisis on Children in Developing Countries: Round 3 Preliminarily Findings, Oxford: Young Lives.

Kabeer, N. (2000) 'Inter-generational Contracts, Demographic Transitions and the 'QuantityQuality' Tradeoff: Parents, Children and Investing in the Future', Journal of International Development 12: 463-82.

Le Thuc, D. (2009) The Effect of Early-age Stunting on Cognitive Achievement among Children in Vietnam, Working Paper 45, Oxford: Young Lives.

Levine, R., C. Lloyd, M. Greene and C. Grown (2008) Girls Count: A Global Investment and Action Agenda, Washington: Center for Global Development.

Luthar. S., D. Cicchetti and B. Becker (2000) 'The Construct of Resilience: A Critical Evaluation and Guidelines for Future Work', Child Development 71, 543-62.

Pells, K. (2011) Poverty and Gender Inequalities: Evidence from Young Lives, Policy Paper 3, Oxford: Young Lives.

Sanchez, A. (2009) Early Nutrition and Cognitive Achievement in Pre-School Children in Peru, Working Paper 57, Oxford: Young Lives.

Seccombe, K. (2002) "“Beating the Odds" Versus "Changing the Odds": Poverty, Resilience, and Family Policy', Journal of Marriage and Family 64: 384-94.

UNESCO (2010) Reaching the Marginalised: EFA Global Monitoring Report 2010, Paris: UNESCO. 
UNICEF (2010) State of the World's Children 2011: Adolescence-An Age of Opportunity, New York: UNICEF.

Werner, E. and R. Smith (2001) Journeys from Childhood to Midlife: Risk, Resilience and Recovery, Ithaca: Cornell University Press.

Figure One

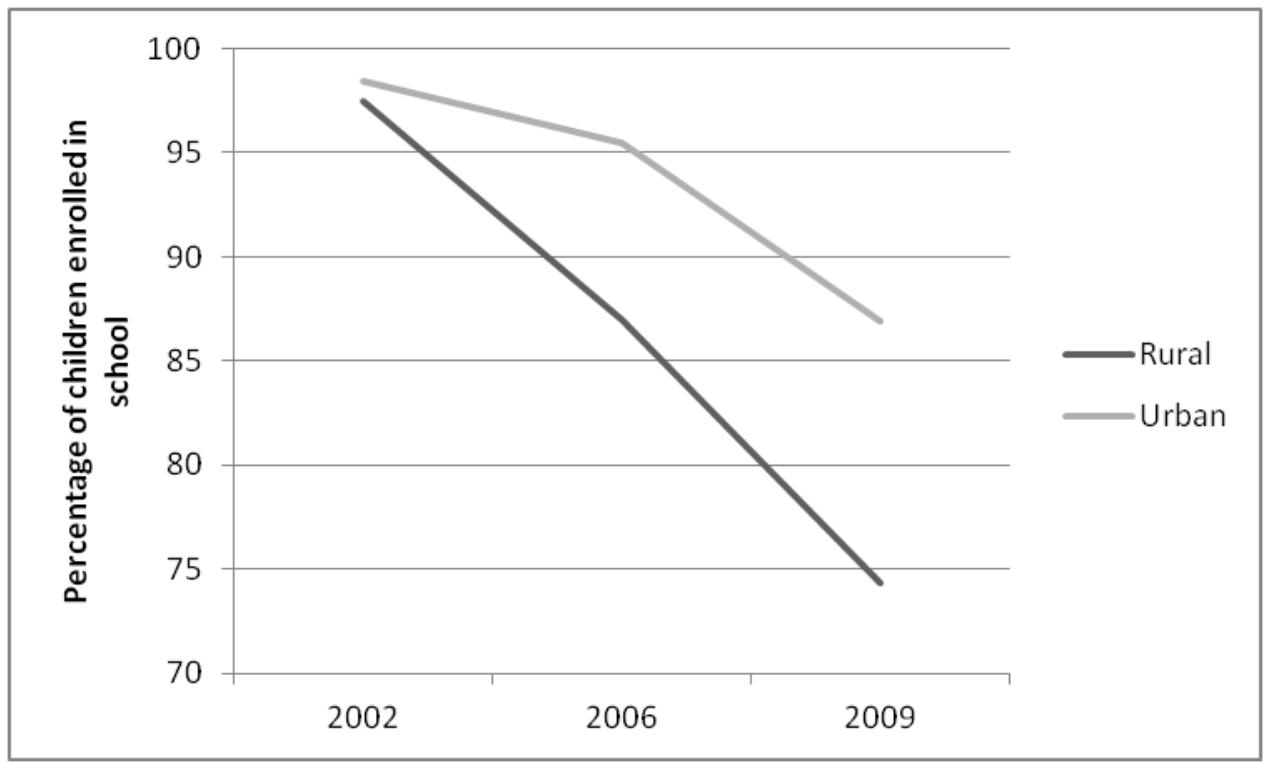

Figure Two

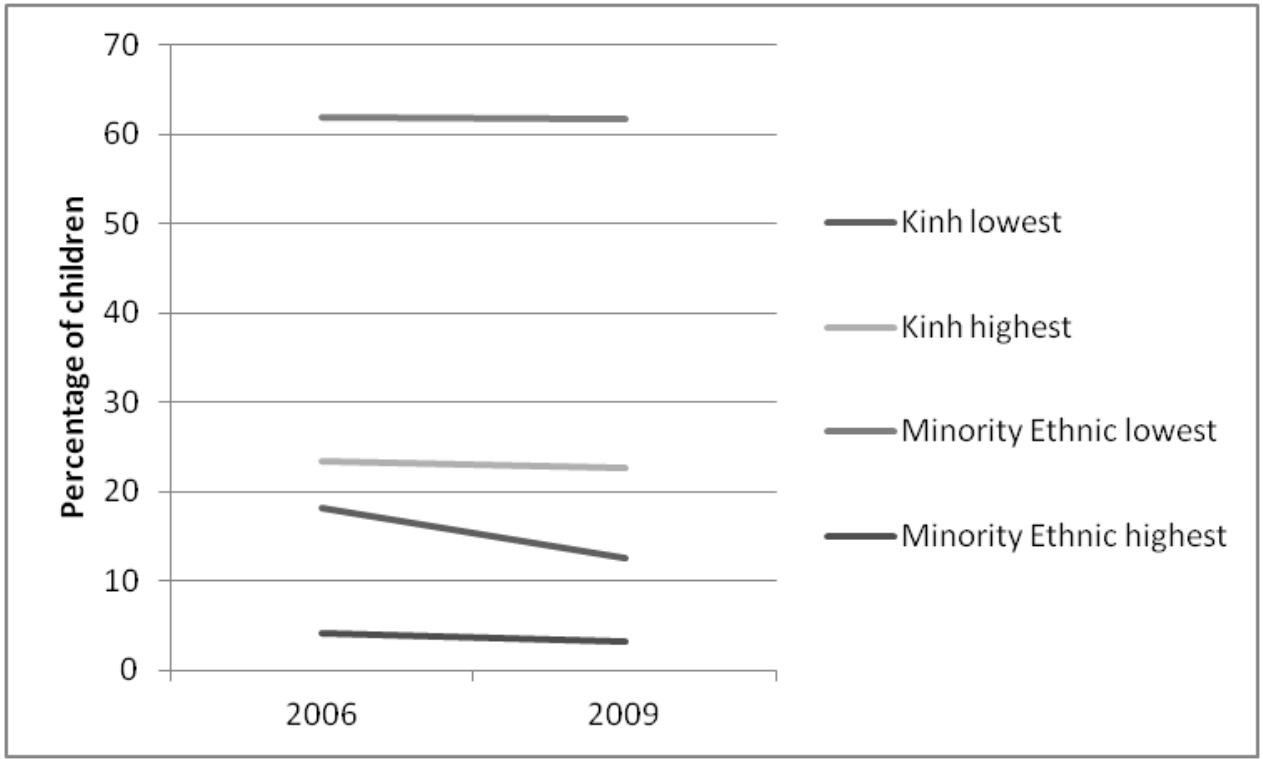


Table One

\begin{tabular}{|l|l|l|}
\hline & \multicolumn{2}{|l|}{$\begin{array}{l}\text { Children not enrolled or poor cognitive } \\
\text { achievement AND out of healthy range of height- } \\
\text { for-age or BMI-for-age (n. =308) }\end{array}$} \\
\hline Group & \% & Number of cases \\
\hline $\begin{array}{l}\text { Boys } \\
53.6 \% \text { of sample }\end{array}$ & 52.6 & 162 \\
\hline $\begin{array}{l}\text { Girls } \\
\text { 46.4\% of sample }\end{array}$ & 47.4 & 146 \\
\hline $\begin{array}{l}\text { Rural } \\
\text { 23.5\% of sample }\end{array}$ & 59.4 & 183 \\
\hline $\begin{array}{l}\text { Urban } \\
76.5 \% \text { of sample }\end{array}$ & 40.6 & 125 \\
\hline $\begin{array}{l}\text { Mestizo } \\
\text { 78.8\% of sample }\end{array}$ & 70.6 & 214 \\
\hline $\begin{array}{l}\text { Ethnic minorities } \\
\text { 17.3\% of sample }\end{array}$ & 25.4 & 77 \\
\hline $\begin{array}{l}\text { White/Asian } \\
\text { 4\% of sample }\end{array}$ & 4.0 & 12 \\
\hline $\begin{array}{l}\text { Consumption quintile 1 } \\
\text { (lowest) }\end{array}$ & 26.4 & 81 \\
\hline Consumption quintile 2 & 21.2 & 65 \\
\hline Consumption quintile 3 & 20.8 & 64 \\
\hline Consumption quintile 4 & 17.9 & 55 \\
\hline $\begin{array}{l}\text { Consumption quintile 5 } \\
\text { (highest) }\end{array}$ & 13.7 & 42 \\
\hline
\end{tabular}

